\title{
Toothpick impaction in the sigmoid colon as a cause of chronic abdominal pain
}

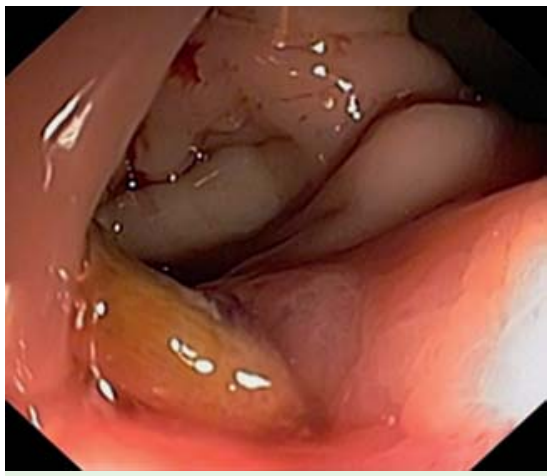

Fig. 1 The endoscopic appearance of the toothpick at the rectosigmoid junction.

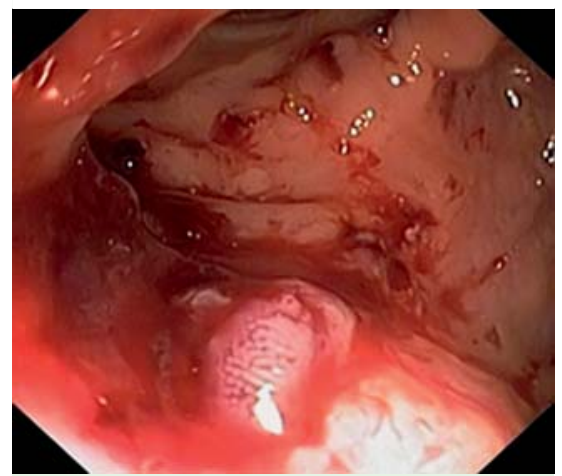

Fig. 2 The endoscopic appearance of impacted colonic mucosa after removal of the toothpick.

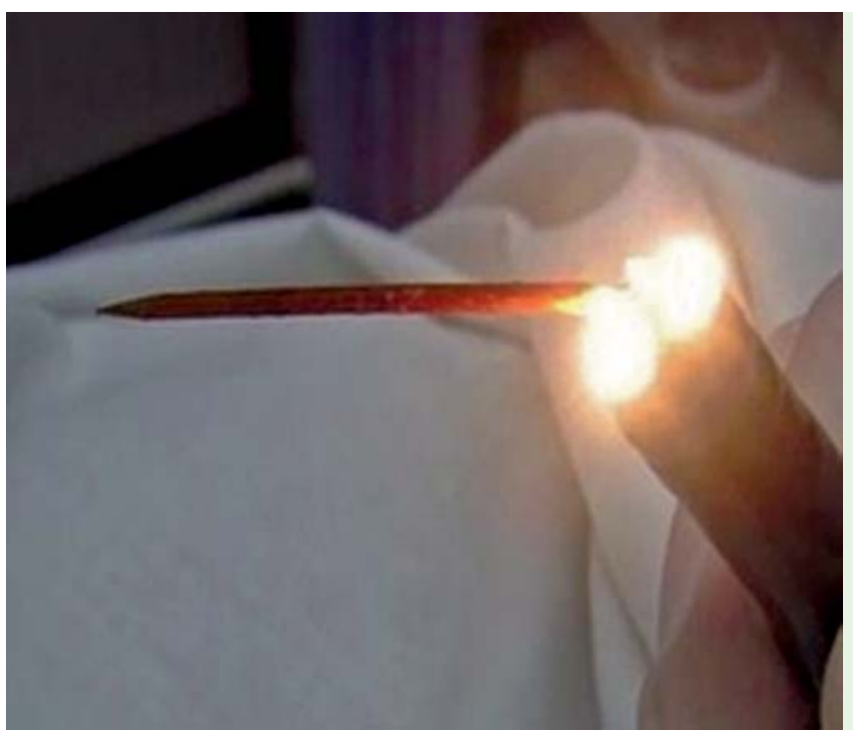

tract, such as the pylorus, the ligament of Treitz, the ileocecal valve, or the rectosigmoid junction [2]. Accidental ingestion of long, narrow, or pointed foreign bodies, such as a toothpick, is associated with a higher risk of impaction and perforation of the gastrointestinal wall, with surgical intervention being required in 15-35\% of cases [2,3]. Sensitivity of endoscopy in detecting gastrointestinal foreign bodies is estimated to be about $70 \%$ compared with $9 \%, 15 \%$, and $29 \%$ for radiography, CT scan, and ultrasonography, respectively [4]. When impaction of such foreign bodies is diagnosed in time, successful endoscopic management is possible.

\section{Competing interests: None}

\section{Endoscopy_UCTN_Code_CCL_1AB_2AF}

\section{R. Grabysa ${ }^{1}$, R. Łowczak ${ }^{1}$, M. Kubiak ${ }^{1}$, M. Kowalczyk ${ }^{2}$, P. Zaborowski ${ }^{1}$}

1 Department of Internal Diseases, Gastroenterology and Hepatology, University Hospital, Warmia and Mazury University, Olsztyn, Poland

2 Department of General and Minimally Invasive Surgery, University Hospital, Warmia and Mazury University, Olsztyn, Poland

\section{References}

1 Eisen GM, Baron TH, Dominitz JA et al. Guideline for the management of ingested foreign bodies. Gastrointest Endosc 2002; 55: 802 806

2 Reddy SK, Griffith GS, Goldstein JA et al. Toothpick impaction with localized sigmoid perforation: successful colonoscopic management. Gastrointest Endosc 1999; 50: $708-709$

3 Webb WA. Management of foreign bodies of the upper gastrointestinal tract. Gastroenterology 1988; 94: 204-216

4 Li SF, Ender K. Toothpick injury mimicking renal colic: case report and systematic review. J Emerg Med 2002; 23: 35-38

\section{Bibliography}

Dol $10.1055 / \mathrm{s}-0030-1255702$

Endoscopy 2010; 42: E203

(c) Georg Thieme Verlag KG Stuttgart · New York . ISSN 0013-726X

\section{Corresponding author \\ R. Grabysa, MD, PhD}

Department of Internal Diseases, Gastroenterology and Hepatology

University Hospital

Warmia and Mazury University

Warszawska 30

10082 Olsztyn

Poland

Fax: +48-89-5413093

rgraby@wp.pl the surface of the impacted colonic mucosa $(\bullet$ Figs. 2 and 3$)$.
Complications after foreign body ingestion occur at sites of angulation or physiologic narrowing of the gastrointestinal 